\title{
Transition to practice in pediatric cardiac surgery: Preparation, execution, and balance
}

\author{
Sergio A. Carrillo, MD, ${ }^{\mathrm{a}}$ and Daniel J. DiBardino, $\mathrm{MD}^{\mathrm{b}, \mathrm{c}}$
}

\footnotetext{
From the acChildren's Heart Center-Nevada, Las Vegas, Nev; the bepartment of Surgery, University of California San Diego School of Medicine, and ${ }^{\mathrm{c}}$ Department of Cardiovascular Surgery, Rady Children's Heart Institute, San Diego, Calif.

Disclosures: Authors have nothing to disclose with regard to commercial support

Received for publication July 15, 2015; revisions received Jan 4, 2016; accepted for publication Feb 7, 2016; available ahead of print March 11, 2016.

Address for reprints: Daniel J. DiBardino, MD, The Rady Children's Heart Institute, 3020 Children's Way, MC 5078, San Diego, CA 89109 (E-mail: daniel.dibardino@gmail.com).

J Thorac Cardiovasc Surg 2016;151:1457-9

$0022-5223 / \$ 36.00$

Copyright (C) 2016 by The American Association for Thoracic Surgery

http://dx.doi.org/10.1016/j.jtcvs.2016.02.011
}

The word transition dates back to the 16th-century Latin word transitio or transire, which means to go across. It is the process or period of changing from 1 state or condition to another. For us, the most recent (and by far the most difficult) transition was from trainee to independent attending surgeon. We have previously discussed that the term independent in this context is subjective and somewhat of an illusion because many senior surgeons rely on their partners during difficult cases or during especially tough times. ${ }^{1}$ Somewhat paradoxically, this process begins well before graduation from training, as the angst of becoming an independent practitioner grows. We knew the stakes were high in surgery. For many of us, that was among the attractions. As a trainee, you are ultimately always protected-both medically and legally_and you know that this is coming to an end during your final 6-month stretch. Suddenly, you might pay a little more attention when assisting or read a little more before a case than in the preceding months. Preparing for the Board exams during this time can actually be comforting and productive.

As you stand in an operating room alone for the first time, suddenly you realize exactly how high the stakes actually are. The helping hand, sage wisdom, and experience of your long-time residency mentors are absent. The circulating nurse begins asking what kind of materials you will use at the same time the perfusionist approaches you to discuss cannulae choices and perfusion strategy. You are the person solely responsible for the outcome of your patients. This is something you have been waiting for. It is both exciting and frightening.

We are currently facing many challenges in the state of health care as our careers evolve and develop. One of these is the outcry for accountability and public reporting of outcomes. The onus is on us to provide the best possible care to all patients, effectively raising the bar. ${ }^{2}$ These professional challenges coexist with our personal lives and a balance must be found to achieve professional and individual satisfaction for a successful career and home life. ${ }^{3}$ There are

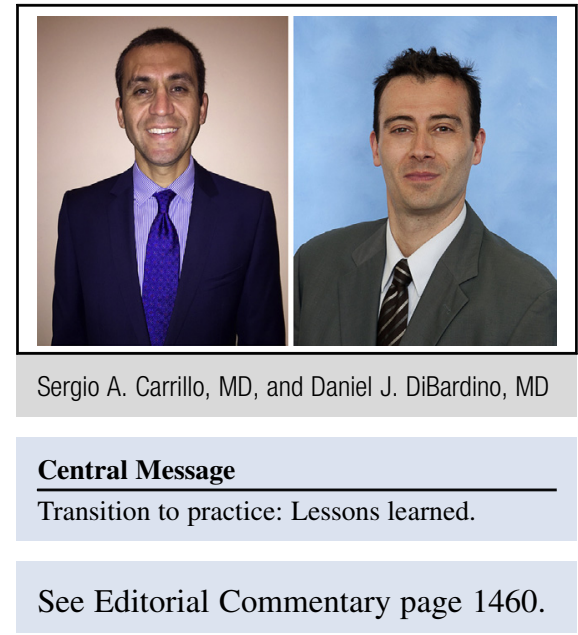

ways of managing this transition, including your choice of job (and especially) your partners, how you interact and use your partners and colleagues, how you manage your expert niche and referrals, and how you manage your free time. In the remainder of this invited commentary we discuss what our approach has been to these various aspects of transition.

\section{MANAGING THE TRANSITION: JOBS, MENTORS, NICHES, AND BALANCE}

As you prepare for the Board exam during the home stretch of your training, your transition continues with the job search. You will quickly realize that as the most junior cardiac surgeon, you are initially nothing more than a liability for your surgical partner(s) and largely a nuisance to pediatric cardiologists. Choosing your first job wisely can influence whether you succeed or fail in practice. It is our opinion that ongoing mentorship is the most important factor in the success of achieving independent practice. Remember that the term independent is a misnomer-the focus of any practice is on collaboration, not being independent! Resist the temptation to focus your job search primarily on the weather, region, or lifestyle. Rather, focus on who you will be partnering with. Unless you are an anomaly (we cannot think of a single example), you do not enter solo practice as a first job.

Identifying the right partners can be more difficult than it sounds. You are relying on some honesty in terms of these folks being genuinely interested in taking on this role for you. Not everyone is as good at this as they say they are. Has the chief ever taken on a new partner before, and if 
so, what was the outcome? You must recognize, to the best of your ability, whether these partner(s) will commit to you and continue the mantle of mentorship that you became so used to in residency. Second, it is ideal to find someone who will allow you to incorporate your learned skills and techniques into the practice, creating a bidirectional exchange benefiting you both. In return, as you grow your partner(s) will enjoy more time off from work, extra time to pursue other interests, and program expansion.

During your job search, identify areas of weakness and strength. Analyze what the program lacks or boasts and, importantly, how you might fit in. It may be the case that what Program A really needs is an adult congenital heart surgeon, whereas Program B needs a surgeon with lung transplantation experience. Those programs may not be a fit for you if your interest is in ventricular assist devices or neonatal cardiac surgery. Try to find the best match and compromise with the understanding that there is not a true perfect fit. Go where your talent and skills will be recognized and be prepared to let the needs of the program retrain your interests a bit. A busy surgeon who does lung transplants here and there is better than being an unemployed surgeon who does not do any lung transplant procedures!

After beginning your surgery practice, try to learn from your mistakes and even more importantly, from those of others. This requires willingness to have open and honest discussions about near-misses and mistakes during specific procedures. First have these discussions with yourself, then with your partner(s) in a private setting. This is intimately linked to your learning curve. Once tolerated and even expected, learning curves continue to be a necessary evil even in the current era of litigation and denial and intolerance on the part of many referring doctors. ${ }^{4}$ A recent study ${ }^{3}$ looking at the learning curves in cardiac surgery suggests that new pediatric cardiovascular surgeons can learn to perform new and complex operations without experiencing the same learning curve that their mentor went through. This was shown by a senior surgeon mentoring new staff in the arterial switch operation and the Norwood procedure. Keep a detailed recording of your personal outcomes and complications and write about these in a personal surgeon journal. You never have to share it with anyone if you do not want to, but such clear and thoughtful analysis will speed up your learning curve and allow you to be proud of your progress.

You probably should expect (and welcome) your partner(s) as surgical assistant(s) in the very beginning. Far from an admission of defeat, this is both protective for you and allows your partner(s) to gauge your progress and keep you out of trouble. You will be at a time in your career at which a single bad outcome in your first 4 cases will cause serious speculation about your ability. If your partner is there, he or she will shoulder some of the blame. After 104 cases, this loses its value. As your numbers grow, outcomes improve, and practice succeeds, expect more independence and less reliance on your physician team. Some of the best surgeons we have worked with (some the best congenital heart surgeons in the world) still call their partners from time to time. If they believe this is important, you should too. This continuous growth and maturity will blossom and strengthen ties with referring cardiologists. Developing strong ties with your referring cardiologists is advantageous. Whether there is 1 or more cardiology practices surrounding your program, these relationships will cement your status in the community.

Once you have overcome your personal learning curve, measuring your success is important. There are many ways to do this. Certainly, tracking and publishing your results and performing quality improvement projects is gratifying and will now be expected by the American Board of Thoracic Surgery in 5- and 10-year recertification efforts. As pediatric cardiac surgeons, among of the most interesting ways to measure our success is by the ability to handle unforeseen problems in the operating room. Handling a complication with skill, knowledge, and professionalism requires confidence and experience and is a genuine marker of growth. In the business world, this is referred to as fluid intelligence and is considered an inherent trait of leadership. It is the ability to manage one's self and one's relationships in times of complexity and high stress. ${ }^{5}$ These characteristics will stand out and make you a leader in your hospital, practice, and community. Do not rush to be a nationally recognized heart surgeon. Start by being a leader within your surgical team and the rest will follow.

Career development is often overlooked. In a universitybased practice, finding mural or extramural funding will be highly desired. Novel ideas and innovations come from having an open mind for change. For example, we are being called more often to the catheterization laboratory for hybrid approaches to conventional open surgery. This allows a close relationship with interventional pediatric cardiologists that benefits patients. Get your ideas printed on paper and begin writing articles describing your techniques and observations. Oral presentations or face time at local, regional, national, or international meetings to showcase your ideas and opinions, will expand your repertoire of acquaintances, provide a forum for networking, and show your leadership within our community of surgeons. In a private-based practice, you will be asked to be involved with hospital administrators and to take on leadership roles such as quality improvement committee member, safety initiatives champion, or director of surgical services, among many others.

As your career reaches new heights, consider expanding your educational portfolio by pursuing additional academic titles such as a master's degree in public health or a doctorate in basic science, whilst not forgetting to pay forward what you have been taught by educating the next 
generation of leaders in our specialty (eg, medical students, surgical residents, fellows, and allied health personnel).

With success comes an increase in the demand of your time and your life balance will be tipped, with the professional side usually winning over the personal side. Such is the reality of virtually all cardiothoracic surgeons. As new regulatory efforts on work-hour restrictions have been implemented during the past decade, the gap between the demands and obligations as resident and as practicing surgeon is getting larger. In actuality, the 80-hour work week you were accustomed to will no longer be relevant and you do whatever it takes to get the sickest patients off of extracorporeal membrane oxygenation and out of the hospital. During these busy times, do not let the weekends be your time to catch up on paperwork, billing, dictations, and work on articles and new projects. One of the authors (SAC) has found that a daily regimen that includes morning exercise, family time, and professional duties works most of the time! Fortunately, there will be also be slower weeks to catch up with family and friends. Allow yourself to plan vacation time in advance, and if possible, at regular intervals. All of this sounds daunting and perhaps overwhelming, but despite many career demands, career satisfaction has traditionally been high among cardiothoracic surgeons. ${ }^{6}$

It is no surprise that nearly half of surgeons recently surveyed in a poll about the demands of the profession ${ }^{7}$ agreed that these demands create imbalance in their relationships with spouses and children. Establishing what balance means to one person is not necessarily what provides balance to another. Assuming distinct responsibilities at home and participating in childcare is a necessity for most. We also adamantly believe that daily exercise plays an important role in this balance. Although most of us advise exercise to our patients, few actually incorporate it in daily life. ${ }^{8}$ The activity of a busy workday alone will not provide the recommended level of physical activity by the American Heart Association. ${ }^{9,10}$ Weight gain (invariably associated with lack of exercise and unhealthy eating and drinking habits) is almost always a sign of imbalance and should trigger some changes in your routine. Taking time to enjoy the company of others and explore new hobbies can also have a positive influence on one's personal life and should not be underestimated.

\section{CONCLUSIONS}

The transition from resident to independent surgeon is a lifelong process, not a graduation day. ${ }^{1}$ It is a difficult process, but there are techniques to manage some aspects in addition to common sense, hard work, and commitment to patients. Begin to think about this process as you finish your training, focus on Board exam preparation, and think about being in surgical situations alone. Looking for your first job is very important and should be based almost entirely on your future partners' ability to serve as mentors. Recognizing how you will fit into the existing practice is essential. Do not be afraid to rely on your partners in the beginning. This can shorten your learning curve. Self-regulation in addition to introspection, affability, flexibility, time management skills, teamwork, outside-of-work interests, and life balance are important for your personal success. Do not forget that, in the end, what matters the most is the happiness of you and your family.

\section{References}

1. DiBardino DJ. Transition from residency to "independent" congenital heart surgeon: a lifelong process, not a graduation day. World J Pediatr Congenit Heart Surg. 2013;4:328-9.

2. Jacobs JP. Caring for patients with congenital cardiac disease - introduction to part 6 of the supplement. Cardiol Young. 2005;15(suppl 1):159-60.

3. Cohen MS, Jacobs JP, Quintessenza JA, Chai PJ, Lindberg HL, Dickey J, et al Mentorship, learning curves and balance. Cardiol Young. 2007;17(suppl): 164-74.

4. Bull C, Yates R, Sarkar D, Deanfield J, de Leval M. Scientific, ethical, and logistical considerations in introducing a new operation: a retrospective cohort study from paediatric cardiac surgery. BMJ. 2000;320:1168-73.

5. Goleman D, Boyatzis R, McKee A. Primal leadership. Boston: Harvard Business Press; 2002.

6. Shemin RJ, Dziuban SW, Kaiser LR, Lowe JE, Nugent WC, Oz MC, et al. Thoracic surgery workforce: snapshot at the end of the twentieth century and implications for the new millennium. Ann Thorac Surg. 2002;73:2014-32.

7. Jacobs JP, Ungerleider RM, Tchervenkov CI, Ebels T, Laliberté E, Maruszewski B, et al. Opinions from the audience response survey at the First Joint Meeting of the Congenital Heart Surgeon's Society and the European Congenital Heart Surgeons Association. Semin Thorac Cardiovasc Surg Pediatr Card Surg Annu. 2005;8:198-217.

8. Reed BD, Jensen JD, Gorenflo DW. Physicians and exercise promotion. Am J Prev Med. 1991;7:410-5.

9. Abd TT, Kobylivker A, Perry A, Miller Iii J, Sperling L. Work-related physical activity among cardiovascular specialists. Clin Cardiol. 2012;35:78-82.

10. Haskell WL, Lee IM, Pate RR, Powell KE, Blair SN, Franklin BA, et al. Physical activity and public health: updated recommendation for adults from the American College of Sports Medicine and American Heart Association. Circulation. 2007;116:1081-93. 